\title{
Understanding the Thermal Cracking for Anthracene Molecule : A DFT Approach
}

\author{
Muthana A. Shanshal* and Qhatan A.Yousif** \\ *Department of Chemistry, College of Science, Baghdad University. \\ ** Department of Chemistry, College of Science, Al-Qadisiya University.
}

\begin{abstract}
Density Functional Theory (DFT) calculations were carried out to study the thermal cracking for anthracene molecule to estimate the bond energies for breaking the following bonds $\mathrm{C} 1-\mathrm{C} 2$, $\mathrm{C} 1-\mathrm{C} 9 \mathrm{a}, \mathrm{C} 9-\mathrm{C} 9 \mathrm{a}, \mathrm{C} 2-\mathrm{C} 3, \mathrm{C} 1-\mathrm{H} 1, \mathrm{C} 2-\mathrm{H} 2$, and $\mathrm{C} 9-\mathrm{H} 9$ as well as the activation energies. The activation energy values for $\mathrm{C} 1-\mathrm{H} 1, \mathrm{C} 2-\mathrm{H} 2$, and $\mathrm{C} 9-\mathrm{H} 9$ bond breakage is lower than required for $\mathrm{C} 1-\mathrm{C} 2, \mathrm{C} 1-$ $\mathrm{C} 9 \mathrm{a}$, and C9-C9a. The carbon - hydrogen bond rupture depends only slightly on the position in the molecule so the values of reaction energy is close to $117 \mathrm{kCal} / \mathrm{mol}$ and unlike the carbon-carbon bonds. It seems that the characteristic planarity is important factor to acquire the molecule structure the required stability along the reaction paths. The trends in the bond energies and the configuration structures are discussed.
\end{abstract}

Keywords : Thermal cracking, C-H rupture, C-C rupture, DFT, anthracene.

\section{Introduction}

Petroleum or crude oil as a complex mixture of many hydrocarbons[1]. Aromatic compounds are present in high concentrations in crude oil and composited about $3-4 \%$ of the heavy crude oil[2]. The term cracking applies to the decomposition of petroleum where by the higher molecular weight constituents of petroleum are converted to low molecular weight products [3]. Cracking reactions involve carbon-carbon and carbon-hydrogen bonds rupture [4]. The energy associated with a chemical bond, called the bond dissociation enthalpy" energy" (BDE), is measured as the energy required for the reaction. BDE is a fundamental factor influencing chemical reactivity [5]. Bond dissociation energy is recognized as a measure of bond strength and is widely utilized for the estimated of heats of formation of organic chemistry[6]. It is not easy to determine the carbon-carbon and carbon - hydrogen bonds dissociation energies of polyaromatic hydrocarbon experimentally. Thus, the computational chemistry has made impressive advances in the calculation of highly accurate bond energies [7]. For this propose the present study is devoted to the determination the bond energies of $\mathrm{C} 1-\mathrm{C} 2, \mathrm{C} 1-$ C9a,C9-C9a,C1-H1,C2-H2, and C9-H9 bonds for anthracene molecule as well as the conformations for the transition states and reaction products by DFT.

\section{Computational methodology}

Quantum chemical calculations employing DFT[8] are carried out to investigate the energies of $\mathrm{C} 1-\mathrm{C} 2, \quad \mathrm{C} 1-\mathrm{C} 9 \mathrm{a}, \mathrm{C} 9-\mathrm{C} 9 \mathrm{a}, \mathrm{C} 1-$ $\mathrm{H} 1, \mathrm{C} 2-\mathrm{H} 2$, and $\mathrm{C} 9-\mathrm{H} 9$ bonds. All calculations are conducted using the Gaussian [9] 2009 suite programs in the workstation that have the high performance in the CPU process and memory size.DFT allows to compute all properties of systems by the electron density, $\rho(r)$ which is a function of three variables, $\rho(\mathrm{r})=\mathrm{f}(\mathrm{x}, \mathrm{y}, \mathrm{z})$. The hybrid DFT method is included a mixture of Hartree-Fock exchange with DFT exchange-correlation. Also, this method known as hyper - GGA functional [9.10]. The most popular hybrid functional is known B3LYB and was suggested by Stephenes. In B3LYP, the PWal correlation functional is replaced by the LYP functional. B3 (Becke three parameter hybrid functionals, these functionals have the form devised by Becke, LYP is the Lee - Yang Parr correlation functional [10.11]. Recent work has suggested that B3LYP approach is the best functional for the calculation of hydrocarbon bond energies [7.12].Significant improvement in the agreement between electronic structure calculations and experiment can be achieved by increasing the number of basis set functions. Thus, The triple-zeta (TZ) basis set such as 6-311G [11.13] used in the present work. 


\section{Results and Discussion}

The energies required to break $\mathrm{C}-\mathrm{H}$ and $\mathrm{C}-\mathrm{C}$ bonds have been calculated by virtue of the singlet and triplet states. By examining the potential energy curves one can deduce whether a particular reaction pathway for bond breakage is favoured in comparison with other pathways. The carbon and hydrogen atoms of the anthracene molecule are numbered in conformity with the convention laid down by the International Union of Pure and Applied Chemistry (IUPAC) [14] for the regular naming of chemical compounds (Scheme(1)). Furthermore, Scheme (1) displays the atomic charges for each of the atoms by means of various colours denoting $-0.16 \mathrm{C}$ to $0.16 \mathrm{C}$.

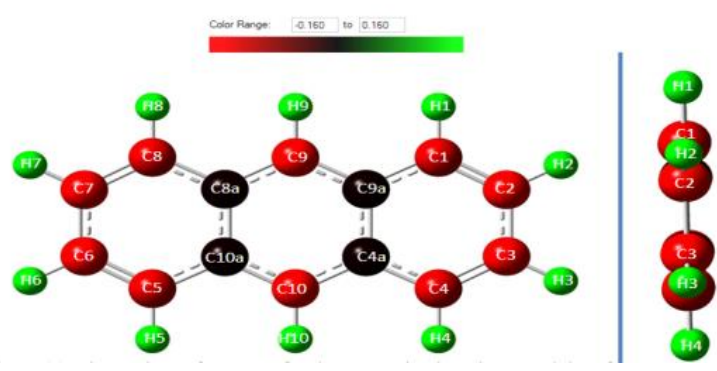

Scheme (1) Shows the configuration of anthracene molecule with compatibility of atomic.

Table (1) shows the bonds lengths between C1-C2 in Angstrom units and the bond energies both in atomic units and in kilocalories per mole. It reveals the activation energy that is required, forming a transition state with a bond length of $3.5 \AA$, whereas the C1-C2 bond breaks in the singlet state with a bond length of $3.6 \AA$ (yielding the reaction energy). The potential energy curve for the C1-C2 bond (Fig.(1)) reveals the magnitude of the activation energy and the reaction energy at the singlet state, $(192.50 \mathrm{kCal} / \mathrm{mol})$ and $(125.20 \mathrm{kCal} / \mathrm{mol})$, respectively.
Table (1)

Shows the bonds lengths for anthracene molecule in Angstrom units and the bond energies both in atomic units and in kilocalories per mole for C1-C2 bond breakage.

\begin{tabular}{|c||c|c||c||}
\hline $\begin{array}{c}\text { Bond } \\
\text { length } \\
(A)\end{array}$ & $\begin{array}{c}E \\
(\text { a.u })\end{array}$ & $\begin{array}{c}\Delta E \\
(\text { a.u })\end{array}$ & $\begin{array}{c}\Delta E \\
(K C a l / m o l)\end{array}$ \\
\hline \hline 1.24 & -539.4991457 & 0.018897 & 11.85817 \\
\hline 1.36 org. & -539.5180429 & 0.000000 & 0.000000 \\
\hline 1.66 & -539.4741953 & 0.043848 & 27.51479 \\
\hline 1.96 & -539.4047926 & 0.113250 & 71.06564 \\
\hline 2.26 & -539.3444348 & 0.173608 & 108.9407 \\
\hline 2.46 & -539.3112198 & 0.206823 & 129.7835 \\
\hline 2.66 & -539.2830147 & 0.235028 & 147.4824 \\
\hline 2.86 & -539.2590480 & 0.258995 & 162.5218 \\
\hline 3.06 & -539.2385326 & 0.279510 & 175.3954 \\
\hline 3.2 & -539.2288644 & 0.289179 & 181.4623 \\
\hline 3.3 & -539.2229042 & 0.295139 & 185.2023 \\
\hline \hline 3.5 T.S. & -539.2112627 & 0.306780 & 192.5075 \\
\hline 3.6 & -539.3185109 & 0.413217 & 125.2082 \\
\hline 3.8 & -539.3231345 & 0.553692 & 122.3069 \\
\hline 4 & -539.3147022 & 0.188780 & 127.5982 \\
\hline \hline
\end{tabular}

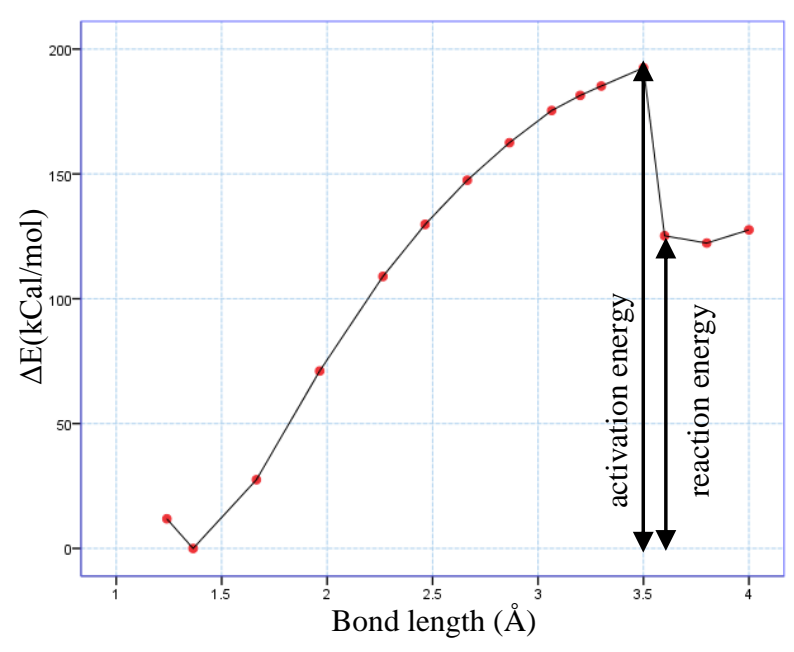

Fig.(1) Shows the potential energy curve for anthracene molecule which includes the activation energy and reaction energy for C1-C2 bond breakage. 
The pictorial representation (2) exhibits the transition state, the product of the cleavage of the $\mathrm{C} 1-\mathrm{C} 2$ bond, and the atomic charges for each the atoms (distinguished by means of colour). In the transition state, the molecule becomes non planar and forms a double bond (C2-C3), single bond (C4a-C9a) and resonance bonds $(\mathrm{C} 3, \mathrm{C} 4, \mathrm{C} 5)$.

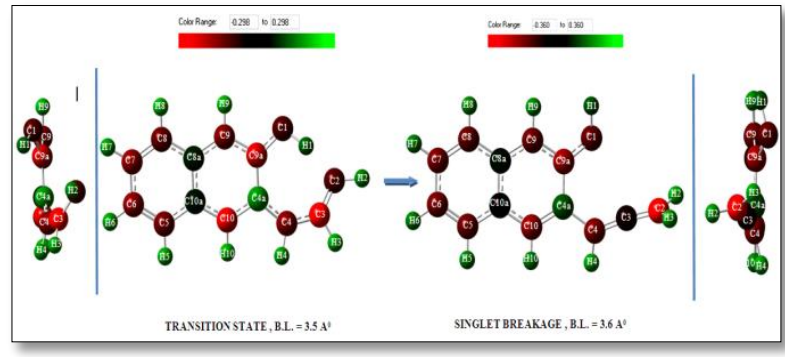

Scheme (2) Exhibits the transition state, the product of the cleavage of the C1-C2 bond, and the atomic charges for each the atoms (distinguished by means of colour).

Furthermore, rotation about the $\mathrm{C} 3-\mathrm{C} 4$ bond axis is possible. The appearance of resonance bonds between the carbons atoms accounts for compensation of the electronic decrease which results from breaking the bond between the $\mathrm{C} 1$ and $\mathrm{C} 2$ atoms. In the singlet state at a bond length of $3.6 \AA$, the hydrogen atom (H3) is transferred to the carbon atom (C2) and forms two successive double bonds (between $\mathrm{C} 2, \mathrm{C} 3$ and $\mathrm{C} 4$ ). resulting in an allene structure that is unshared with other rings by a resonance process because the single bond is constituted between the carbon atoms ( $\mathrm{C} 4$ and $\mathrm{C} 4 \mathrm{a}$ ) and consequently the structure of the molecule becomes more distorted. This modification to the structure of the molecule allows most atoms in the molecule to attain a full octet [15] and thus stabilize the molecular structure. Fig.(2) shows the atomic charges for $\mathrm{C} 1$ and $\mathrm{C} 2$ which confirms that the $\mathrm{C} 1-\mathrm{C} 2$ breaks beyond a bond length of.3.6

Fig.(3) exhibits the activation energy $(156.04 \mathrm{kCal} / \mathrm{mol})$ at a bond length of $3.4 \AA$ and the reaction energy value $(133.47 \mathrm{kCal} / \mathrm{mol})$ at a bond length of $3.5 \AA$ in the triplet state. Scheme (3) depicts the mechanism of the cleavage of the C1-C9a bond at a length of $3.5 \AA$ in the triplet state, in addition to the spatial geometry of the transition state at a bond length $3.4 \AA$ including the atomic charges for all atoms in the molecule.

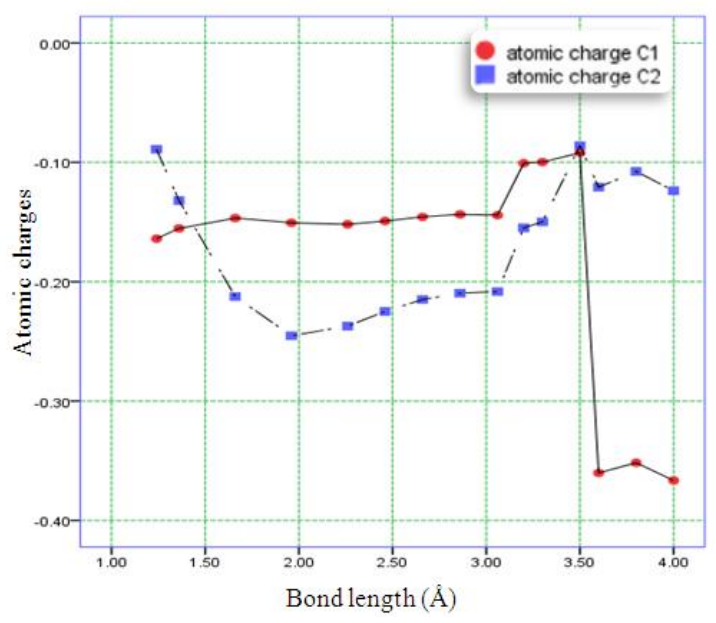

Fig.(2) Shows the atomic charges for C1 and C2 of anthracene molecule.

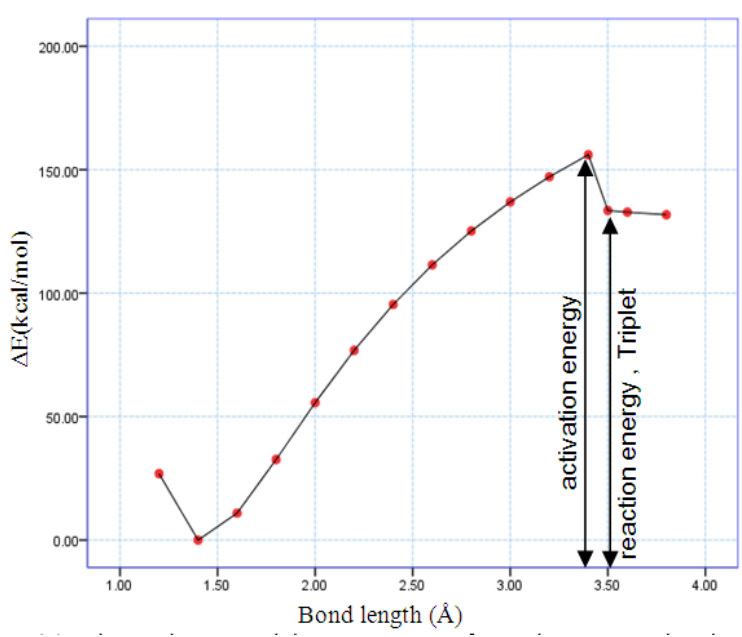

Fig. (3) Shows the potential energy curve for anthracene molecule for C1-C9a bond breakage.

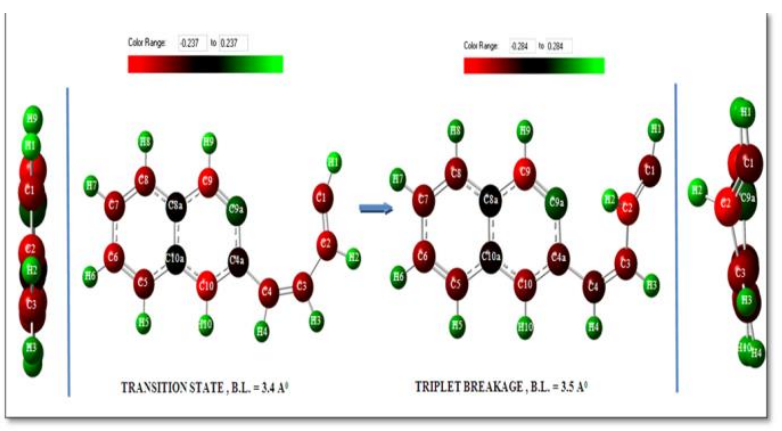

Scheme (3) Exhibits the transition state, the product of the cleavage of the C1-C9a bond, and the atomic charges for each the atoms (distinguished by means of colour). 
In the transition state, the configuration of the open hydrocarbon chain contains a double bonds between carbon atoms (C1-C2 and C3-C4) and single bonds between carbon atoms $(\mathrm{C} 2-\mathrm{C} 3$ and $\mathrm{C} 4-\mathrm{C} 4 \mathrm{a})$ whilst retaining the characteristic planarity of aromatic compounds. As soon as the electronic spin changes, the rotation around the $\mathrm{C} 2-\mathrm{C} 3$ bond axis occurs and, as a result, the two hydrogen atoms ( $\mathrm{H} 2$ and $\mathrm{H} 3)$ will become aligned in a trans-configuration. Fig.(4) confirms the cleavage of the $\mathrm{C} 1-\mathrm{C} 9 \mathrm{a}$ bond at a length of $3.5 \AA$ in the triplet state.

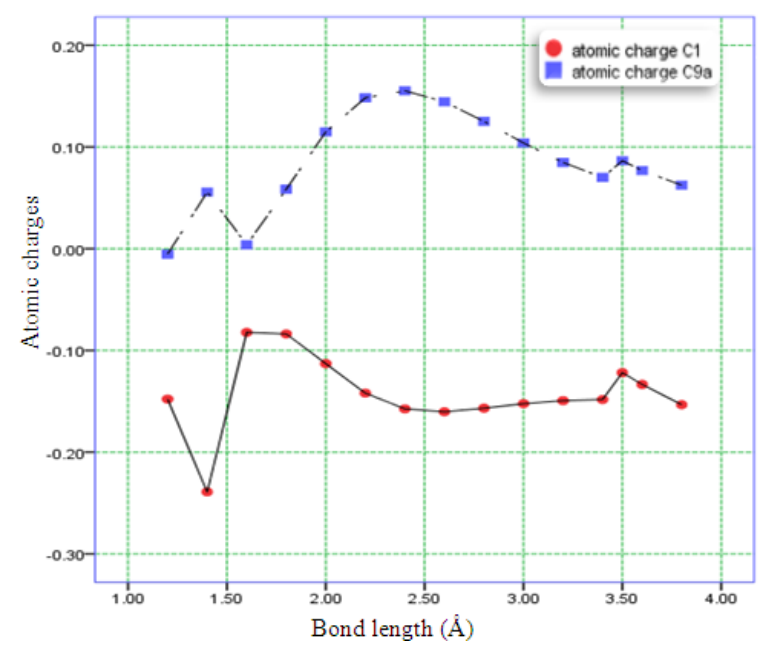

Fig.(4) Shows the atomic charges for C1 and C9a of anthracene molecule.

The activation energy value (202.86 $\mathrm{kCal} / \mathrm{mol}$ ) and the reaction energy value $(156.97 \mathrm{kCal} / \mathrm{mol})$ following the singlet state pathway are shown in Fig.(5).

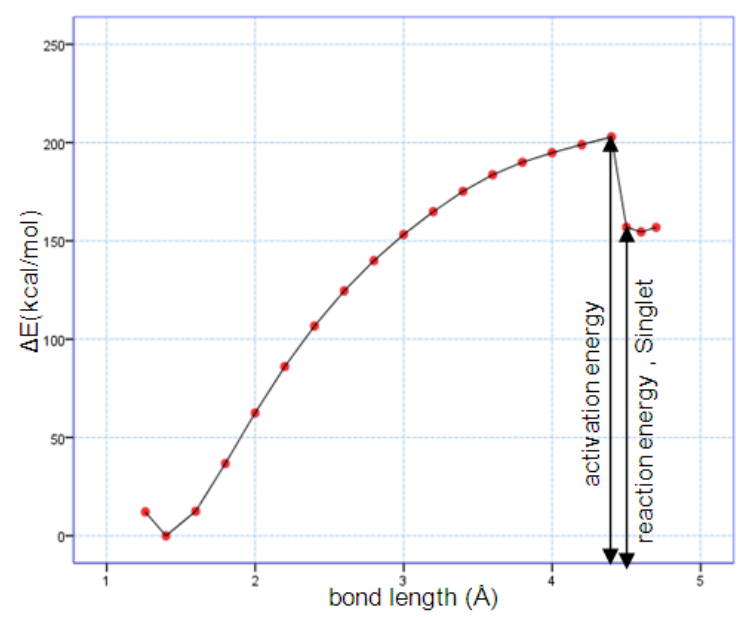

Fig.(5) Shows the potential energy curve of anthracene molecule for C9-C9a bond breakage.
The mechanism of the reaction that includes a transition state structure and the breaking of the $\mathrm{C} 9-\mathrm{C} 9 \mathrm{a}$ bond is described by means of Scheme (4).

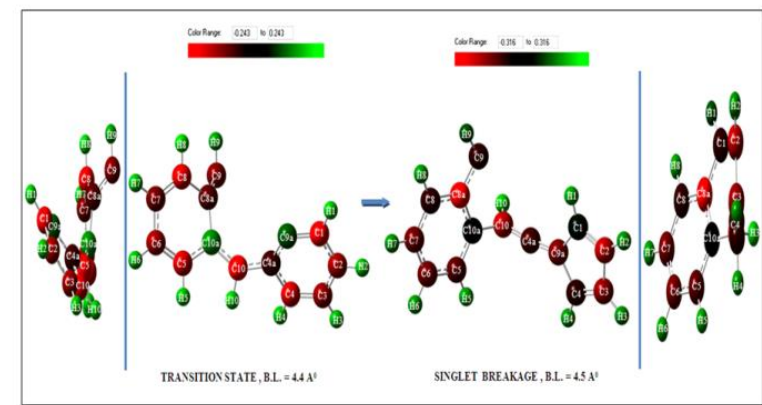

Scheme (4) Exhibits the transition state, the product of the cleavage of the C9-C9a bond, and the atomic charges for each the atoms (distinguished by means of colour).

Firstly, in the transition state the single bonds are formed and rotation occurs around the $\mathrm{C} 10-\mathrm{C} 10 \mathrm{a}$ bond axis accompanied by loss of the characteristic planarity of aromatic compounds. Whilst retaining the electron spin, but at a bond length of $4.2 \AA$ the molecule is configured as a five-membered ring and a pure allene (uncombined by resonance). In addition, the benzene ring in the molecule achieves an aromatic $\pi$-sextet [16]. This modification in the structural geometry will give the required stability for the structure by allowing the atoms in the molecule to achieve a stable octet. Thus, the data contained in Fig.(6) support the cleavage of the C9-C9a bond at a bond length of $4.2 \AA$.

The values for the activation energy $(149.75 \mathrm{kCal} / \mathrm{mol})$ and the reaction energy $(117.32 \mathrm{kCal} / \mathrm{mol})$ via a triplet state pathway are exhibited in Fig.(7). Scheme (5) can be invoked to discuss the reaction mechanism that includes the cleavage of the $\mathrm{C} 1-\mathrm{H} 1$ bond via a transition state structure. 


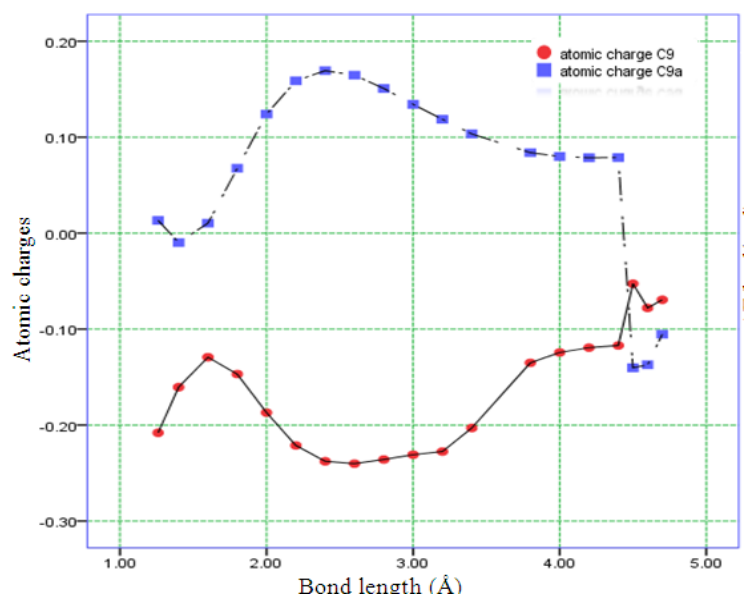

Fig. (6) Shows the atomic charges for C9 and C9a of anthracene molecule.

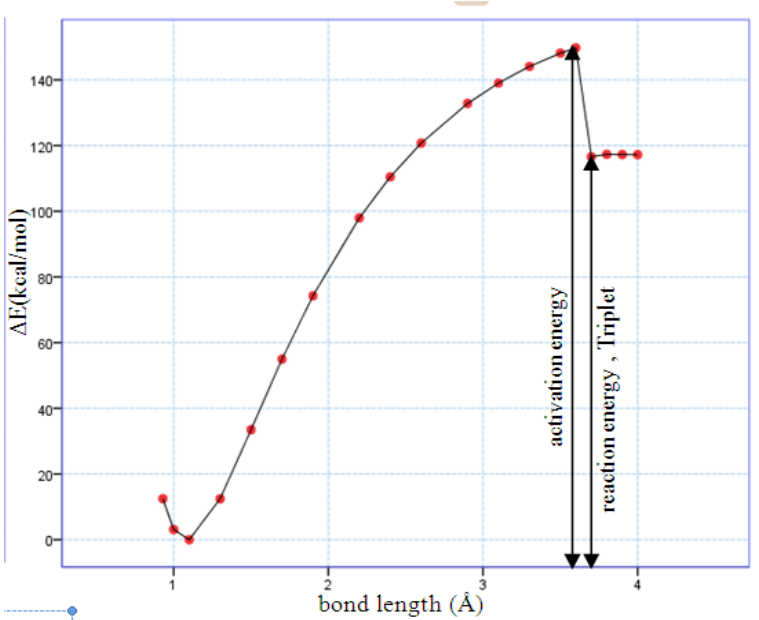

Fig.(7) Shows the potential energy curve for anthracene molecule for C1-H1 bond breakage.

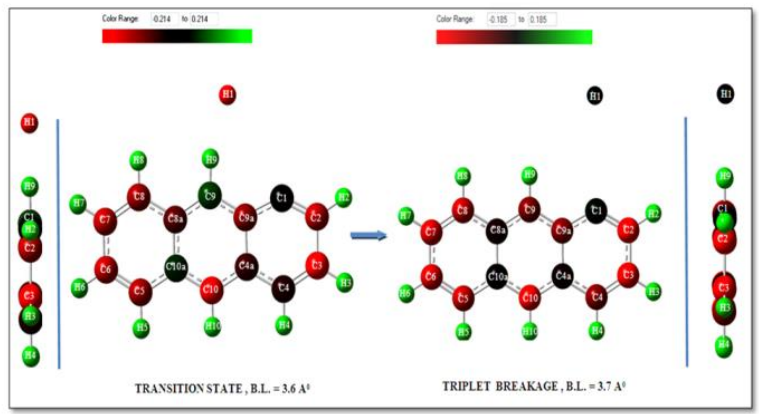

Scheme (5) Exhibits the transition state, the product of the cleavage of the C1-H1 bond, and the atomic charges for each the atoms (distinguished by means of colour).
In the transition state the two single bonds (C2-C3 and C4a-C9a) are formed as well as the removal of the hydrogen atom $\mathrm{H} 1$ from the molecule. This is accompanied with a deviation from the reaction path in the sense that the interaction is unequal between the hydrogen atoms $\mathrm{H} 1$ and H9. Similarly, at the bond length of $3.7 \AA$ the two single bonds (C4a-C9a and C8a-C10a) are formed along with the loss of the hydrogen atom $\mathrm{H} 1$ as a free radical far from the planar molecule. Both the two structures preserve the characteristic planarity of aromatic compounds. The conversion of atomic charges for carbon atom $\mathrm{C} 1$ and hydrogen atom $\mathrm{H} 1$ from positive values into the negative values and those close to zero, that refer to the release of the hydrogen atom $\mathrm{H} 1$ as a free radical without any interactions with other atoms are exhibited in Fig.(8). Moreover, Fig.(8) supports the cleavage of the $\mathrm{C} 1-\mathrm{H} 1$ bond at a bond length of $3.7 \AA$.

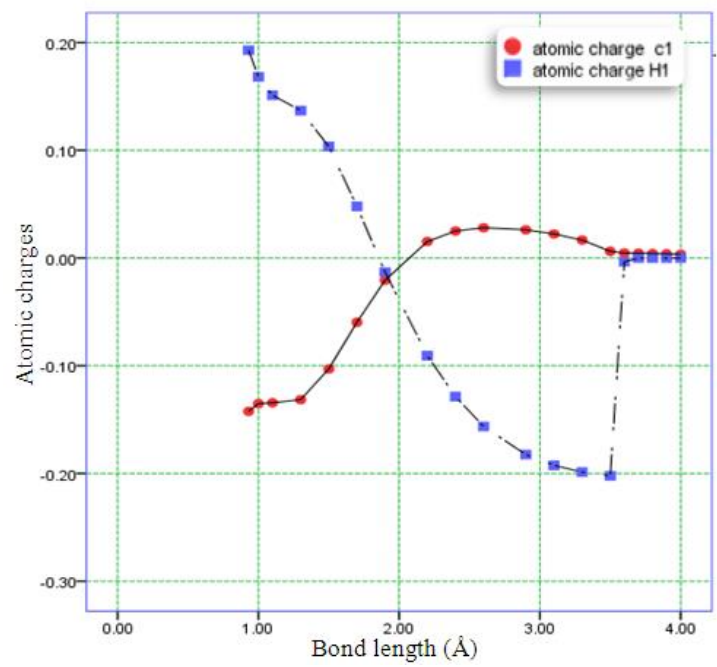

Fig.(8) Shows the atomic charges for C1 and H1 to anthracene molecule.

Fig.(9) display the values of activation energy and reaction energy by virtue of the triplet state pathway $(148.41 \mathrm{KCal} / \mathrm{mol})$, $(117.60 \mathrm{KCal} / \mathrm{mol})$, respectively. Knowing the behaviour of the breaking $\mathrm{C} 2-\mathrm{H} 2$ bond can be used to generate Scheme (6) which includes the transition state structure and the geometrical structure at a bond length of $3.4 \AA$. The diagram also contains coloured coded atomic charges. Firstly, in the transition state the two single bonds (C1-C9a and $\mathrm{C} 4 \mathrm{a}-\mathrm{C} 9 \mathrm{a})$ are formed whilst the hydrogen atom $\mathrm{H} 2$ is 
removed from the molecule with retention by the same plane in the sense that the interaction is experienced equally between the hydrogen atoms $\mathrm{H} 2$ and $(\mathrm{H} 1, \mathrm{H} 3)$. However, at a bond length of $3.5 \AA$ the one single bond $(\mathrm{C} 4 \mathrm{a}-\mathrm{C} 9 \mathrm{a})$ is formed as well as the hydrogen atom $\mathrm{H} 2$ is removed from the molecule as a free radical and moved far from the planar molecule. The two structures both preserve the planarity that is characteristic of aromatic compounds. The conversion of atomic charges for carbon atom $\mathrm{C} 2$ and hydrogen atom $\mathrm{H} 2$ from positive values into negative values and to a value that is close to zero that suggests that the release of the hydrogen atom $\mathrm{H} 2$ as a free radical occurs without any interactions with other atoms (this is shown in Fig.(10). Moreover, the data presented in Fig.(10) provide evidence for the cleavage of the $\mathrm{C} 2-\mathrm{H} 2$ bond at the aforementioned length.

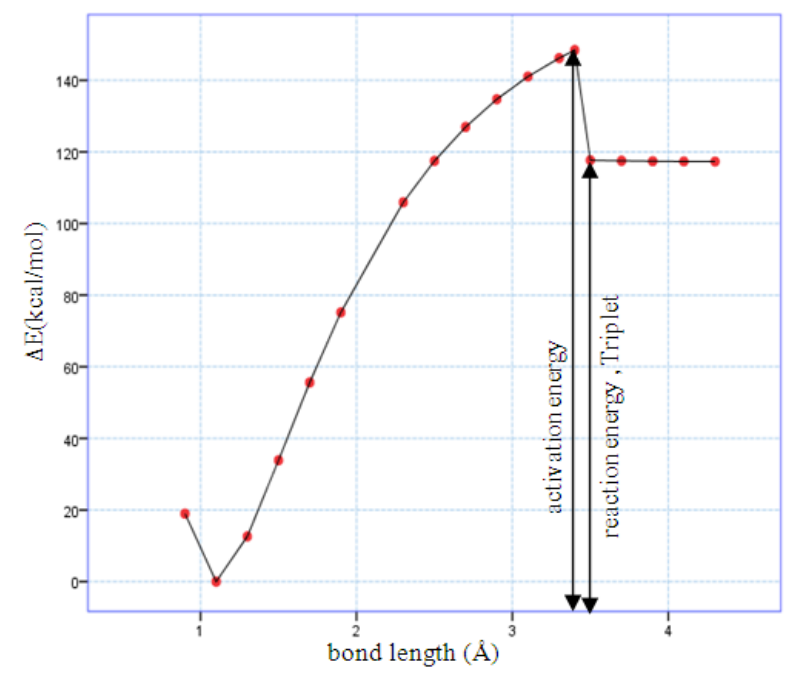

Fig.(9) Shows the potential energy curve for anthracene molecule for $\mathrm{C} 2-\mathrm{H} 2$ bond breakage.

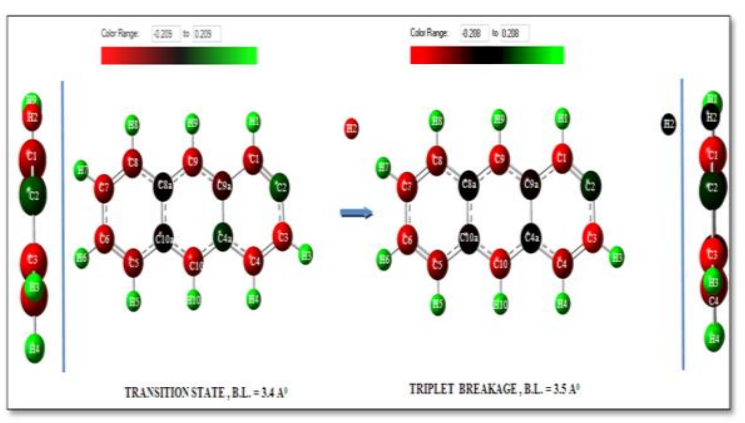

Scheme (6) Exhibits the transition state, the product of the cleavage of the $\mathrm{C} 2-\mathrm{H} 2$ bond, and the atomic charges for each the atoms (distinguished by means of colour).

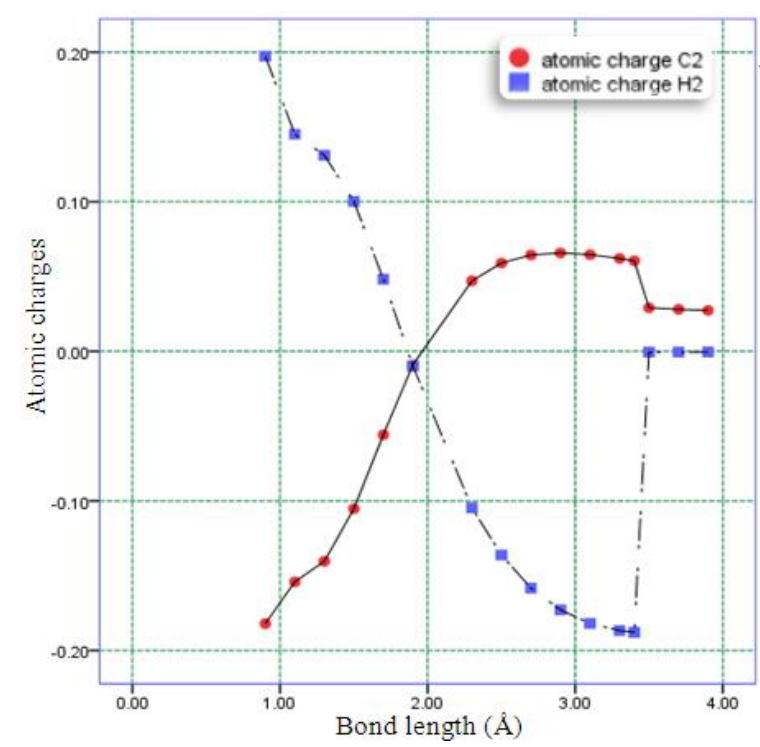

Fig.(10) Shows the atomic charges for C2 and $\mathrm{H} 2$ of anthracene molecule.

Fig.(11) exhibit the values of activation energy and reaction energy by virtue of the triplet state pathway $(156.70 \mathrm{kCal} / \mathrm{mol})$ and (117.34 kCal/mol), respectively. Scheme (7) can be invoked to discuss the reaction mechanism that includes the cleavage of the C9-H9 bond via a transition state structure. In both states, the two single bonds $(\mathrm{C} 8 \mathrm{a}-\mathrm{C} 10 \mathrm{a}$ and $\mathrm{C} 4 \mathrm{a}-\mathrm{C} 9 \mathrm{a}$ ) and an allene fragment (mutual adjacent with other rings through the resonance process) are formed as well and the hydrogen atom $\mathrm{H} 9$ is removed from the molecule with retention in the same plane in the sense that the interaction is equal between the hydrogen atoms $\mathrm{H} 9$ and ( $\mathrm{H} 1$ and $\mathrm{H} 8)$. Thus, at a bond length of $4.1 \AA$ the hydrogen atom H9 is moved away from the molecule as a free radical and moved far from the plane of the molecule. Both the two structures preserve the characteristic planarity. The conversion of atomic charges for carbon atom $\mathrm{C} 9$ and hydrogen atom $\mathrm{H} 9$ from positive values into the negative values and those close to zero refer to the release of the hydrogen atom $\mathrm{H} 9$ as a free radical without any interactions with other atoms have been exhibited in Fig.(12). Moreover, the data in Fig.(12) support the breaking of the $\mathrm{C} 9-\mathrm{H} 9$ bond at the bond length as mentioned earlier. 


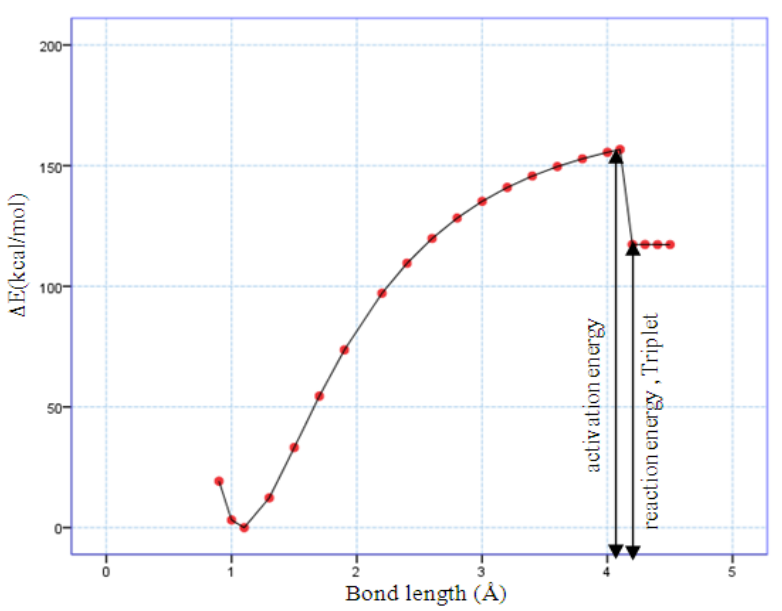

Fig. (11) Shows the potential energy curve of anthracene molecule for $\mathrm{C} 9-\mathrm{H} 9$ bond breakage.

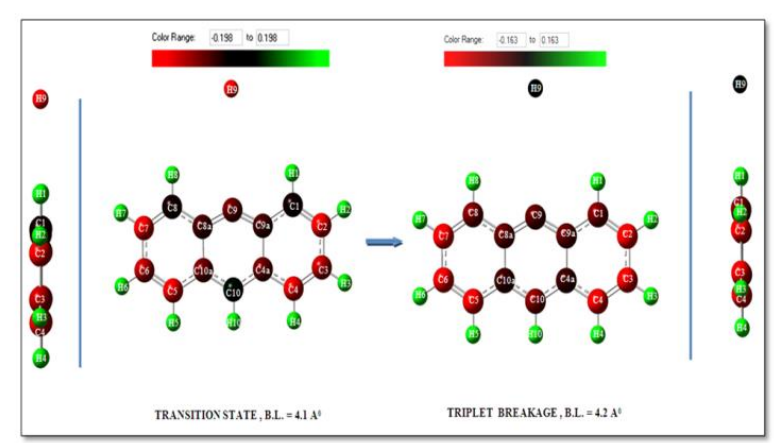

Scheme (7) Exhibits the transition state, the product of the cleavage of the C9-H9 bond, and the atomic charges for each the atoms (distinguished by means of colour).

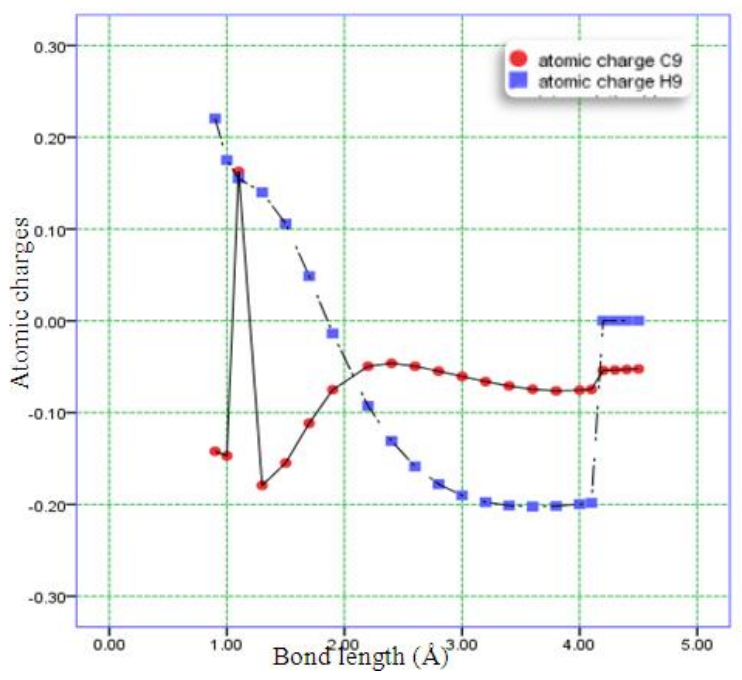

Fig.(12) Shows the atomic charges for C9 and $\mathrm{H} 9$ to anthracene molecule.
Fig.(13) illustrates the potential energy curve along with values for the activation energy and reaction energy for the cleavage of bond $\mathrm{C} 2-\mathrm{C} 3$ in the triplet state.

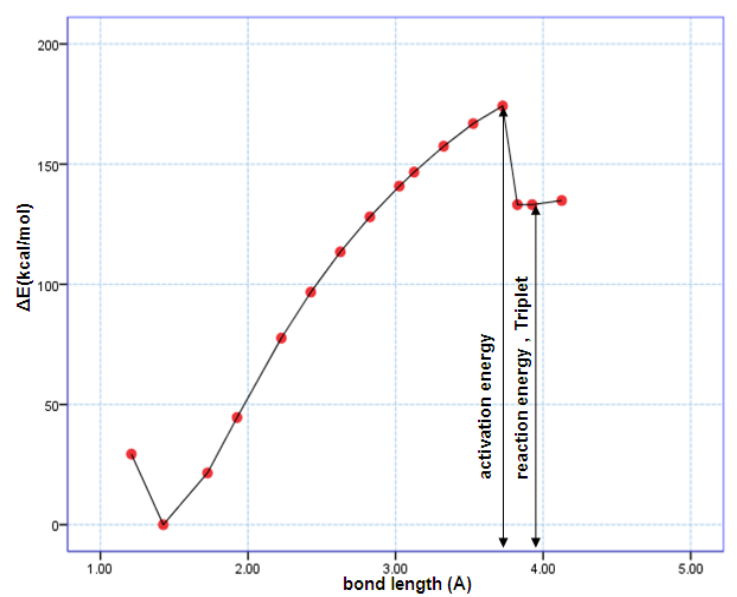

Fig.(13) Shows the potential energy curve of anthracene molecule for $\mathrm{C2}-\mathrm{C} 3$ bond breakage.

Scheme (8) depicts the mechanism of bond cleavage C2-C3 at a bond length of $3.8 \AA$ in triplet state, in addition to the spatial geometry of the transition state at a bond length $3.7 \AA$, including the atomic charges for all atoms in the molecule. Firstly, in the transition state, the double bonds between the carbon atoms $(\mathrm{C} 1$, $\mathrm{C} 2$ and $\mathrm{C} 3, \mathrm{C} 4)$ and the single bonds between carbon atoms $(\mathrm{C} 1, \mathrm{C} 9 \mathrm{a}$ and $\mathrm{C} 4, \mathrm{C} 4 \mathrm{a})$ are formed.

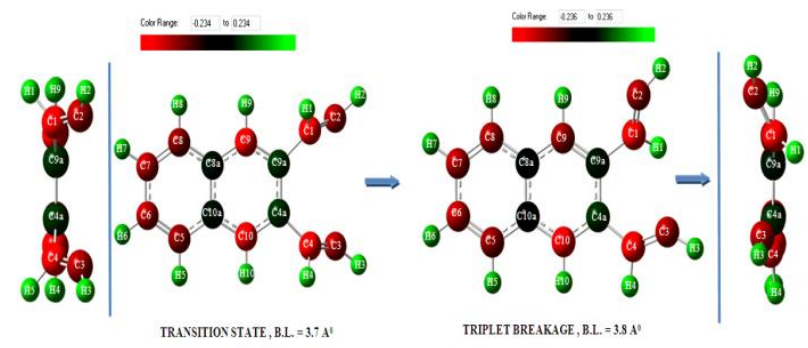

Scheme (8) Exhibits the transition state, the product of the cleavage of the C2-C3 bond, and the atomic charges for each the atoms (distinguished by means of colour).

Ultimately, the change in the electronic spin is accompanied by a change in the configuration of the molecular structure, including a rotation around the $\mathrm{C} 1-\mathrm{C} 9 \mathrm{a}$ bond axis to obtain a structure that is more stable than the transition state. Fig.( ) exhibits clearly that there is no variation in the values of the 
atomic charges as a function of the bond length unless the cleavage of the $\mathrm{C} 2-\mathrm{C} 3$ bond has taken place. This behaviour refers to retention by electronic valence between the two carbon atoms $\mathrm{C} 2$ and $\mathrm{C} 3$ before the $\mathrm{C} 2-\mathrm{C} 3$ bond is broken. Furthermore, the wide range of atomic charges, more than the atomic charges in the ground state, may indicate the stability of the molecular structure in the triplet state. Thus, Fig.(14) confirms that the C2-C3 bond undergoes cleavage at a bond length of $3.8 \AA$.

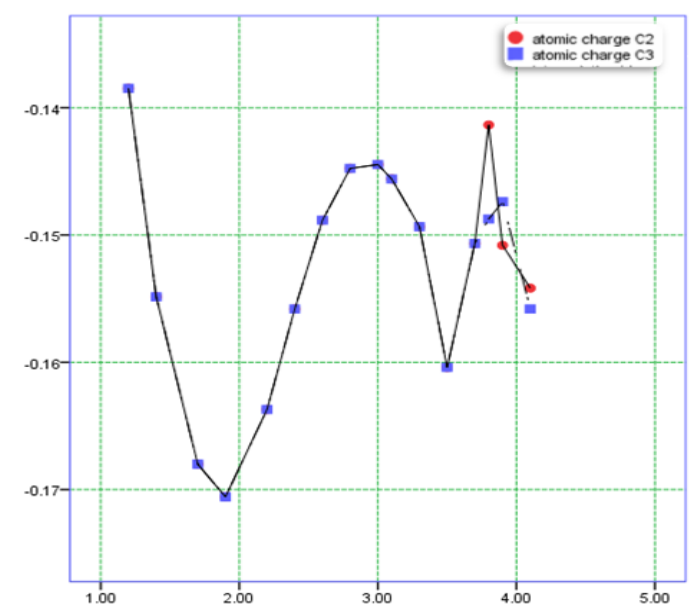

Fig.(14) Shows the atomic charges for C2 and C3 of anthracene molecule.

Table (2)

Summary to values of energies as function to bond length.

\begin{tabular}{|c|c|c|c|c|}
\hline Bond Type & $\begin{array}{l}\text { Activation Energy } \\
\text { Values } \\
(\mathrm{kCal} / \mathrm{mol})\end{array}$ & Bond Length $\AA$ & $\begin{array}{c}\text { Reaction Energy } \\
\text { Values } \\
(\mathrm{kCal} / \mathrm{mol})\end{array}$ & Bond Length $\AA$ \\
\hline $\mathrm{C} 1-\mathrm{C2}$ & 192.50 & 3.5 & 125.20 & 3.6 \\
\hline $\mathrm{C1}-\mathrm{Cga}$ & 156.04 & 3.4 & 133.47 & 3.5 \\
\hline $\mathrm{Cg}-\mathrm{Cga}$ & 202.86 & 4.4 & 156.97 & 4.5 \\
\hline $\mathrm{C} 1-\mathrm{H} 1(\alpha)$ & 149.75 & 3.6 & 117.32 & 3.7 \\
\hline $\mathrm{C} 2-\mathrm{H} 2(\beta)$ & 148.41 & 3.4 & 117.60 & 3.5 \\
\hline C9-H9(solo) & 156.70 & 4.1 & 117.34 & 4.2 \\
\hline $\mathrm{C} 2-\mathrm{C} 3$ & 174.1847 & 3.7 & 133.1606 & 3.6 \\
\hline
\end{tabular}

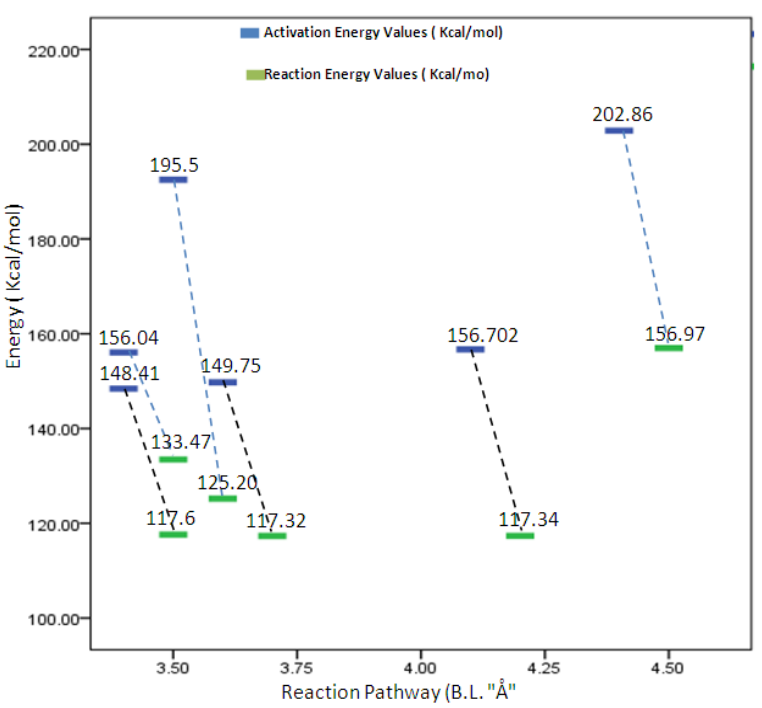

Fig. (15) The relationship between the values of energies in transition state and the final state versus the bond length for anthracene molecule.

Table (2) and Fig.(15) exhibit the data for the present study for comparison purpose. The anthracene molecule an appreciable dramatic change in geometry occurs when $\mathrm{C}-\mathrm{C}$ bond is cleavage as compared with the $\mathrm{C}-\mathrm{H}$ bonds which is a slightly change occurs in geometry owing to the aryl radicals have a nominally singly occupied carbon sp2 orbital orthogonal to the $\pi$-electron system of the aromatic ring. Thus, the general tendency of such an orbital to acquire the maximum degree of $\pi$-character by the quasi-linear geometry (18) about the carbon atom overcomes the ensuring increase in ring strain. Thus, the activation energies values is arranged in the following sequences : $\mathrm{C} 9-\mathrm{C} 9 \mathrm{a}>\mathrm{C} 1-\mathrm{C} 2>\mathrm{C} 1-\mathrm{C} 9 \mathrm{a}$ and $\mathrm{C} 9-$ $\mathrm{H} 9>\mathrm{C} 1-\mathrm{H} 1>\mathrm{C} 2-\mathrm{H} 2$. The low activation energy value for $\mathrm{C} 1-\mathrm{C} 9 \mathrm{a}$ bond due to the transition state is completely planar. The low activation energy value for $\mathrm{C} 2-\mathrm{H} 2$ as well owing to the transitions state is planar and have the good variation for atomic charges via a bond length and the carbon atom is retained by the positive charge as a proceeds the reaction. There are different mechanisms to describe cleavage the carbon - carbon bond as a results to different final products. The low reaction energy value for $\mathrm{C} 1-\mathrm{C} 2$ because the 
structure of the molecule allows most atoms in the molecule to attain a full octet and thus stabilize the molecular structure. The activation energy of solo hydrogen (C9-H9) is high i.e. hydrogen atom bonded to sp2-carbon atoms with no adjacent $\mathrm{C}-\mathrm{H}$ bond. This coincides with the fact that the out-of-plane bending mode of solo-hydrogen at $11.2 \mathrm{~mm}$ is very strong in infrared emission spectra of many ultraviolet-excited nebulae [18]. However, if Table (3) is examined in detail one may note that $\mathrm{C}-\mathrm{H}$ bond dissociation energy depends only on the position of the $\mathrm{C}$ $\mathrm{H}$ bond in the molecule with the opposite to $\mathrm{C}$ $\mathrm{C}$ bond. Therefore, the similar mechanism reaction gives the same end products in conformity with the all values for reaction energy is close to $117 \mathrm{KCal} / \mathrm{mol}$.

\section{Conclusion}

Summarized the following items from the present study :-

1- The energy values decrease sharply after the transition state and the electronic state change its multiplicity to the triplet in $\mathrm{C} 1-\mathrm{C} 9 \mathrm{a}, \mathrm{C} 1-\mathrm{H} 1, \mathrm{C} 2-\mathrm{H} 2, \mathrm{C} 9-$ H9.

2- The formation of a radical following hydrogen atom loss from the anthracene molecule is accompanied by regular changes in the optimized geometry. and due to the $\pi$-character of the radical, it have the intrinsic potential to be stabilized by resonance effects.

3- As $\mathrm{C}-\mathrm{H}$ bond in anthracene molecule are weaker than $\mathrm{C}-\mathrm{C}$ bond, it is reasonable to presume that $\mathrm{C}-\mathrm{H}$ bonds are broken first when a anthracene molecule is exposed to thermal cracking.

4- The C-C bond rupture are mainly determined by steric effects and also by the delocalization process

5- If the aryl radical is formed, the $\mathrm{C}-\mathrm{H}$ bond rupture site will tend to take a quasi- linear geometry with shorter $\mathrm{C}-\mathrm{C}$ bonds. Shortening of C-C bond indicates that this bond is intensified by enhancing $\pi$ - bond character there.

\section{References}

[1] Olah, G.A. "Hydrocarbon chemistry" John Wiely \&Sons publications, First Edition, 2003.

[2] Shanshal, M. and Muala, M.M. "Reaction paths and transition states of $\mathrm{C}-\mathrm{H}$ bond rupture in aromatics, benzene and toluene" Jordan Journal of chemistry, 6,165-173, 2011.

[3] Speright, J.G. "The chemistry and Technology of petroleum" CRC press (Tayler \&Francis publications) Fourth Edition, 2006.

[4] Gary, J. H. and Handwelk, GE. "Petroleum Refining, Technology and Economics" Marcel Dekker publications, Fourth Edition, 2001.

[5] Smith, M.B. and March, J. "March's advanced organic chemistry" Jonh Wiely publications, sixth Edition, 2007.

[6] Luo,Y.R. " Comprehensive handbook of chemical bond energies "CRC press (Tayler \& Francis publications), First Edition, 2007.

[7 Bausclicher, C. W. and Langhoff, S. R. "Bond dissociation energy for substituted Polycyclic aromatic hydrocarbon and their cations" Molecular physics, 96, 471-476, 1998.

[8] Kock, W. and Hoitause, M.C. "A chemist's guide to Density Functional Theory", Wiely-VCH publications, second Edition, 2001.

[9] Frisch, M. J., G. W; Trucks, H. B. Schlegel, G. E. Scuseria and co-worker. Gaussian, Inc., Wallingford CT, 2009.

[10] Sholl, D.S. and Steckel, JA. "Density Functional Theory" John Wiely publications, First Edition, 2009.

[11] Ramachandran, K.I. and Deepa,G. "Computational chemistry and molecular modeling; principles and application" Springer Publications, First Edition, 2008.

[12] Bachrach, S.M. "Computational organic chemistry ", John wiely publications, First Edition, 2007.

[13] Atkins, P. and depaula, J. "Quanta, Matter, and Charges; A molecular approach physical chemistry ", Oxford, First Edition, 2008.

[14] Gokel, G.W. "Dean's handbook of organic chemistry ", McGraw \& Hill press, second Edition, 2003. 
[15] Smith, J.G. "Organic chemistry", McGraw \& Hill press, Third Edition, 2011.

[16] Chattaraj, P. K. "chemical reactivity theory; A density functional view", CRC press (Tayler \&Francis publications), First Edition, 2009.

[17] R.A. and Simnsick, W.J. "Calculated molecular properties of polycyclic Aromatic hydrocarbons" Elseriver publications, New York, First Edition, 1987.

[18] Aiharo, J.I. and Ishida, T. "The C-H bond dissociation of polycyclic aromatic hydrocarbon", Journal of Molecular structure (Theochem), 366, 219-226, 1996.

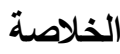

أستُخدمتن حسابات نظرية دوال الكثافة (DFT) لدراسة

C1-C2 , C2-C3, C1-C9a , التكسر الحراري للأواصر , C9-H9 الانثراسين. وتمَ حساب طاقة تتشيط التقاعل (Ea) وطاقة التفاعل لمسلك التفاعل (Err) للحالة البرم الأحادية أو الثلاثية

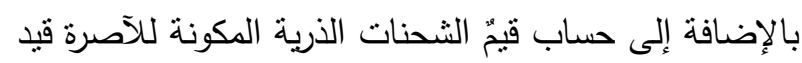

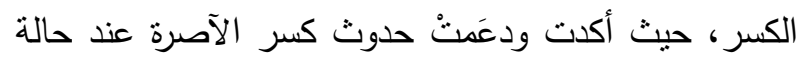
البرم الالكتروني (الأحادي أو الثلاثي ) مقابل طول الآصرة.

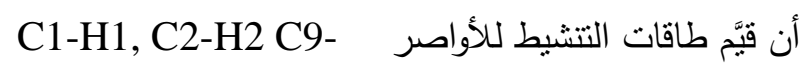
كانت أقل بالمقارنة مع قيَّم طاقات التنشيط للأواصر C1-C9a, C9-C9a C1-C2 , للأواصر C1-H1,C2-H2 C9-H9 كانت متقاربة بحدود الأرة 117 KCal/mol الآصرة وتتابه نواتج التفاعل. صَفة التسطح لمركبات الـ

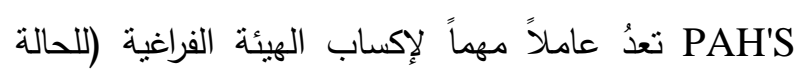

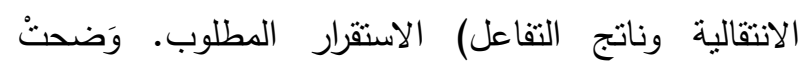
ونُوقتنْ الهيئات الفراغية للحالة الانتقالية ولناتج التقاعل وفق التقاتج حالة البرم الأحادي أو الثلاثي. 